\title{
Employment contracts: the inherent dangers of the fixed-term contract
}

\author{
N. Bigey \\ Attorney at the Paris bar, Mulhouse.
}

\begin{abstract}
Hiring an employee can be risky, especially when choosing the contract that will bind the employer to the employee.

It is essential to choose a suitable contract. Oftentimes, the preferred choice is a fixed-term contract. If the reason for this choice is contested, the financial consequences may be exorbitant.
\end{abstract}

\section{KEYWORDS}

Fixed-term contract, permanent contract, termination of employment contract, Macron ordinances.

Every year, an average of 200,000 employees file claims with the industrial court.

Approximately $80 \%$ of these claims are either partially or completely successful; some are resolved by a ruling in the employee's favor at the end of the proceedings, while others may reach a settlement during the proceedings.

Termination of employment contract is the reason for appeal in eight out of ten cases.

Clinicians in dentofacial orthopedic practices are also affected by this problem. It is therefore clear that changes must be made to any recruitment process to help avoid litigation, especially ones with financial repercussions.
To determine whether a successful candidate is the right fit, many practices use fixed-term contracts (FTCs) on a probationary basis, although their ultimate intention is to switch to a permanent contract.

The reason given by these practices for the use of the so-called "fixed-term contract probation" is the temporary increase in activity.

It is important to remember that according to article L.1242-1 of the Labor Code: "A fixed-term employment contract, regardless of its motive, cannot, neither in its purpose nor its effect, permanently provide a job related to the normal and permanent activity of the enterprise (...) a fixed-term contract can only be concluded on the

Address for correspondence:

Nathalie Bigey - SCP BSP Avocats Associés - 74 rue Jean Monnet

- BP 62093 - 68059 Mulhouse Cedex 2

E-mail: bigey@avocats-mulhouse.com

Article received : 24-03-2018. Accepted for publication : 01-04-2018.

This is an Open Access article distributed under the terms of the Creative Commons Attribution License (http://creativecommons.org/licenses/by/4.0), which permits unrestricted use, distribution, and reproduction in any medium, provided the original work is properly cited. 
basis of the performance of a specific and temporary task, and only in the following cases:

1- Temporary replacement of employees (i.e. sick leave etc.).

2- Temporary increase in activity.

Should the real motive of an FTC be contested, the onus is on the employer and not on the employee to provide proof of its necessity.

This rule has been applied to concluded FTCs, especially in cases of a temporary increase in activity and the replacement of an absent employee.

With regard to using an FTC to replace an absent employee, this may be challenged on the grounds of questionable replacement; for example, the absent employee has resumed his or her duties, but the replacement still works in the office.

With regard to using an FTC due to a temporary increase in activity, this may be challenged on the grounds that there has been no increase in temporary activity. The date of conclusion of FTC is used to assess the validity of this justification, which can only be authorized for the performances of one or more specific tasks, resulting from a single, temporary increase in business activity.

However, the practice of using an FTC in the event of a temporary increase in business activity is risky.

Many practices, when their temporary increase in activity is being challenged, have great difficulty proving that there was indeed an increased patient flow compared with their usual activity.
If the employer is unable to validate its use in this case, various cumulative penalties are incurred.

If its use is invalidated, the FTC is automatically requalified as a permanent contract, following a quick and simplified procedure before the industrial court.

If the employment contract ended because of the term specified in the FTC, this constitutes a dismissal without a real or serious cause since the contract is really one of a permanent or indefinite duration.

The financial penalties are severe:

Requalifying an FTC as a permanent contract results in the following:

- A requalification allowance of one month's gross earnings

- Punitive damages for the abusive termination of the employment contract

- A notice allowance and paid leave for the notice period

- Severance pay to be calculated on a pro rata basis

- The employee will retain a $10 \%$ precariousness allowance on all sums paid to him or her after the resolution of the challenged FTC.

- The employer has a 1-6-month window during which he or she must reimburse Pôle Emploi (French employment agency) for any unemployment benefits paid to the employee.

- An increase in the employer's contribution to unemployment insurance to be maintained by the URSSAF (Organizations for the Collection of Social Security and Family Benefit Contributions). 
As a result, the employer would have to pay a figure equal to several months' worth of the employee's gross salary, an outcome which could have been avoided.

All risks involved in using an FTC for a fictitious temporary increase in activity can be transferred to cases where persons are temporarily hired for a

\section{CONCLUSION}

The only solution to avoid this risk is to use a permanent contract.

It is crucial to have a legal counsel who is an expert in social law and who will draw up a contract that is compliant with all the applicable rules and well-suited to the needs of the practice.

Employers often fear that the duration of the probationary period is not

\section{SUGGESTED WORKS}

Social Status Dictionary, Legislative Editions. temporary increase in activity as well as invalidated FTCs.

We must also remember that once the probationary period has elapsed, the contract can only be terminated due to serious misconduct or by mutual agreement with the employee, a conventional termination of course being excluded.

sufficient to gauge the professional qualities of the recruited employee.

They should bear in mind that permanent contracts can be broken, even after the probationary period, with a significantly reduced and measurable financial risk, provided that their legal counsel is an expert in social law.

Conflict of interest: The author has no conflict of interest.

Social Practical Documentation, Editions Francis Lefebvre. 